\title{
A GENERAL EMPIRICAL MODEL FOR ESTIMATION OF SOLAR RADIATION IN YANGTZE RIVER BASIN
}

\author{
CHEN, J. L. ${ }^{1 *}-$ HE, L. ${ }^{2}-$ WEN, Z. F. ${ }^{1}-$ LV, M. Q. ${ }^{1}-$ YI, X. X. ${ }^{1}-$ WU, S. J. ${ }^{1}$ \\ ${ }^{I}$ Chongqing Institute of Green and Intelligent Technology, Chinese Academy of Sciences \\ 400714 Chongqing, China \\ (phone: +86-23-6593-5555; fax: +86-23-6593-5000) \\ ${ }^{2}$ Key Laboratory of Poyang Lake Wetland and Watershed Research, Ministry of Education \\ 330000 Nanchang, China \\ (phone: +86-23-6593-5555; fax: +86-23-6593-5000) \\ *Corresponding author \\ e-mail: chenjilong@cigit.ac.cn \\ (phone:+86-23-6593-5912; fax: +86-23-6593-5000) \\ (Received $18^{\text {th }}$ Nov 2017; accepted $12^{\text {th }}$ Feb 2018)
}

\begin{abstract}
Solar radiation is the principal and fundamental energy for many physical, chemical and biological processes. Estimation of solar radiation by Ångström-Prescott (A-P) model from sunshine duration is common employed. In this paper, the original linear A-P model and four commonly used modification models (quadratic, cubic, power and logarithmic functions) are comparatively studied. It is found that the linear, second and cubic models give very similar goodness of fit, and the linear model is recommended due to its greater simplicity and convenience. The A-P model parameter $a$, sum $a+b$ correlate most significantly with altitude. Based on these correlations, the deterministic equations of parameters $\mathrm{a}$ and $\mathrm{b}$ are proposed. Consequently, the A-P model with the estimated parameters by deterministic equations is used to estimate solar radiation, and it gives good performance with the RMSE $<1.7 \mathrm{MJ} \mathrm{m}^{-2}$, RRMSE $<20 \%$ and $\mathrm{R}^{2}>0.89$. It is therefore recommended to use these equations to determine the A-P parameters in Yangtze River basin in China, and it is believed particularly useful for the site where lacks of the measured solar radiation data for calibration.
\end{abstract}

Keywords: empirical model, meteorological variable, Angström-Prescott equation, sunshine duration, geographical information

\section{Introduction}

Solar radiation arriving on the earth's surface plays an important role in most land surface processes including physical, biological and chemical processes, e.g., hydrological cycling, vegetation growth, climate and weather change (Liu et al., 2017). It is also one of the key input variables in crop growth, and hydrological and climate models. And the importance of global solar radiation in ecology, agriculture, environment and the associated researches has been well documented (Yorukoglu and Celik, 2006; Chen et al., 2011). However, it is not widely measured due to the cost and difficulty of maintenance and calibration of the measurement equipment (Chen et al., 2013). Only a few meteorological stations measure global solar radiation. For example, in the USA, less than $1 \%$ of meteorological stations are recording solar radiation (Thorton and Running, 1999). In China, more than 2000 stations have record of meteorological data, only 98 stations are recording solar radiation (Chen et al., 2004). The ratio of stations recording solar radiation to those recording temperature is about 1:500 around the world (Thorton and Running, 1999). By contrast, other routinely measured data, such as air temperature, sunshine duration, are easily available. 
Therefore, developing method based on those readily available meteorological data for accurately estimating solar radiation has been the focus of many studies.

Major methods including satellite-derived (Frulla et al., 1988; Chen et al., 2014), stochastic algorithm (Richardson, 1981; Hansen, 1999), empirical relationship (Chen and Li, 2013; Chen et al., 2015), interpolation (Chen et al., 2012) and learning machine method (Chen et al., 2011) have been developed for the purpose. The satellite-derived method is promising for estimating solar radiation data over large regions, but it is relatively new and may suffer from the shortage of the historical meteorological data (Abraha and Savage, 2008). Stochastic weather generators are useful to generate daily simulations from data averages (Wilks and Wilby, 1999). However, the generated data cannot be used for model validation for a particular period of time as the data may not match the actual weather at a particular time. Spatial interpolation technique can predict values at unknown locations and create surface from the surrounding measured points. The main problem, however, is the lack of sufficient stations of solar radiation measurements (Chen and Li, 2014).

The empirical relationship using the easily available meteorological data, such as sunshine duration, maximum and minimum temperatures, is attractive for its simplicity, efficiency and lower data requirement. And the well-known sunshine-based ÅngströmPrescott (A-P) model (Chen and Li, 2013; Chen et al., 2015) and the temperature-based Hargreaves and Samani model (1982), Bristow and Campbell model (1984) are widely used in the word. It is generally recognized that the A-P model performs much better than other temperature-based models (Iziomon et al., 2002; Podesta et al., 2004; Trnka et al., 2005).

The A-P model was proposed by Ångström (Chen et al., 2015) in 1924 and further modified by Prescott (Chen and Li, 2013) in 1940. The original form of the model is (Eq. 1):

$$
R s=\left(a+b \frac{H}{H o}\right) R a
$$

where $R s$ is monthly mean daily global radiation $\left(\mathrm{MJ} \mathrm{m}^{-2} \mathrm{~d}^{-1}\right), R a$ is monthly mean daily extra-terrestrial solar radiation $\left(\mathrm{MJ} \mathrm{m}^{-2} \mathrm{~d}^{-1}\right), H$ is monthly mean daily actual sunshine hours (h), Ho is monthly mean daily potential sunshine hours (h), $a$ and $b$ are empirical parameters which are calibrated from the long-term measured solar radiation data. The A-P model is widely used for its simplicity and significant performance. One of the principal limitations is that it requires calibration using local measured solar radiation data and it is therefore open to question how transferable these calibration values are to other locations (Miller et al., 2008). Ångström suggested values of 0.2, and 0.5, and Prescott 0.22 , and 0.54 for the empirical parameters $a$, and $b$, respectively (Chen and Li, 2013). Page gave the corresponding values of 0.23 , and 0.48 , which was believed to be applicable anywhere in the world (Page, 1961). FAO 56 recommended the values of 0.25 , and 0.50 for parameters $a$, and $b$ for the sites where no solar radiation data is available, respectively (Allen et al., 1998). Lots of literature reported the calibrated the A-P model parameters for different places, and showed that they varied from location to location; furthermore, they were related to the geographic elements (Bandyopadhyay et al., 2008; Liu et al., 2009), indicating that the fixed parameters are not appropriate for all the sites where no solar radiation data is available in a large area. Only a few works 
discussed and gave the determination equations for the A-P model parameters relating to the geographic elements (Bandyopadhyay et al., 2008).

Therefore, the current study is carried out to develop a general empirical model for estimation of solar radiation in Yangtze River basin, which plays significant role in water supply for agriculture industry for China, and hence the eco-environmental models and crop growth simulation are widely studied. However, only a few meteorological stations provide solar radiation recorders. Therefore, solar radiation estimation is of vital importance and significance. While only a few works were reported for this region. Chen et al. (2004) developed an empirical model at 10 located in Yangtze River basin. While this new model was reported to give similar performance with the A-P model (Wu et al., 2007). Therefore, the objectives of the current study are (1) to calibrate the A-P model parameters in the Yangtze River basin; (2) to investigate and relationship between A-P model parameters and geographic elements; and (3) to recommend determination equations of A-P model parameters for the sites where no measured solar radiation data is available for calibration in study area.

\section{Materials and method}

\section{Data set}

The current study focuses on the Yangtze River basin (Fig. 1). The Yangtze River is $6300 \mathrm{~km}$ long with a basin area of $180 \times 10^{4} \mathrm{~km}^{2}$. It is characterized by abundant water resources, and thus plays significant role in water supply for agriculture industry, because economy of much of the Yangtze River basin is focused largely on agricultural production. It is one of the major grain production areas of China and hence the ecoenvironmental models and crop growth simulation are widely studied. A large part of the Yangtze River basin is subtropical monsoon climate. Average annual precipitation in the basin varies from $270-500 \mathrm{~mm}$ in the west to $1600-1900 \mathrm{~mm}$ in the southeast. Average annual sunshine hours range from 1000 to $2500 \mathrm{~h}$.

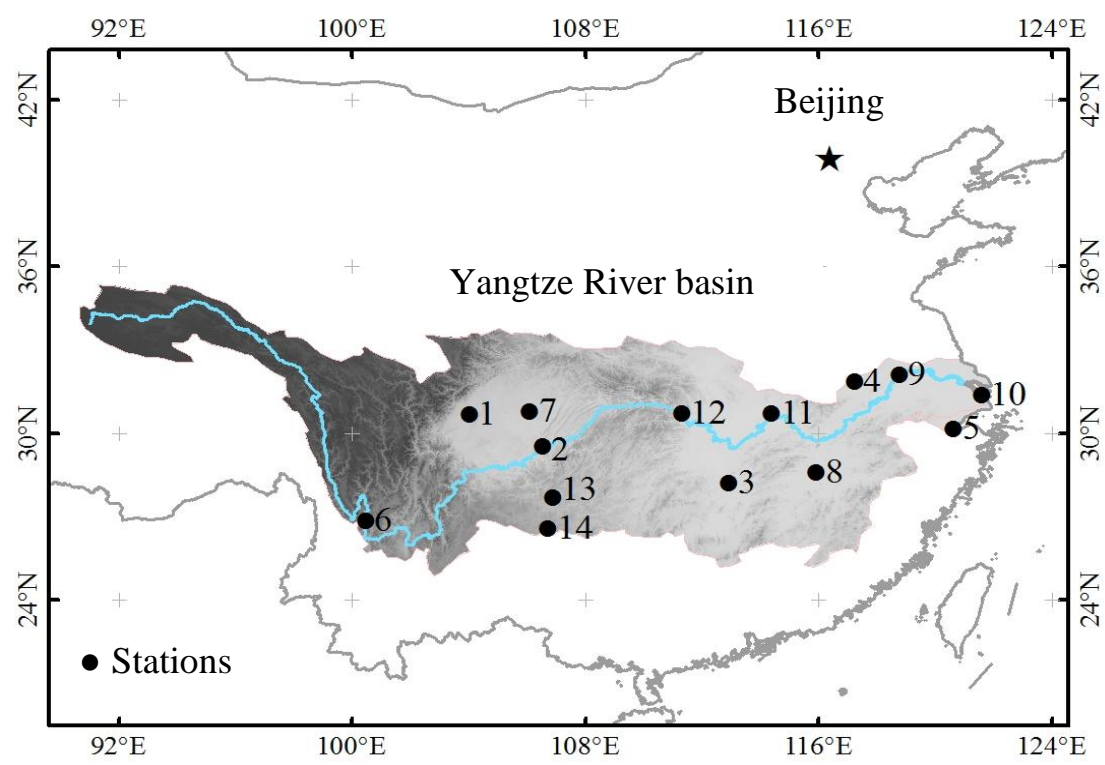

Figure 1. Location of the study meteorological stations in the Yangtze River basin (stations are numbered in compliance with Table 1) 
A total of 14 stations with long-term available records of solar radiation were used in the present study. The mapping of stations roughly range from $26^{\circ}$ to $34^{\circ}$ latitude North, from $97^{\circ}$ to $121^{\circ}$ longitude East, and from 3 to $3394 \mathrm{~m}$ altitude. Table 1 shows the temporal period and the geographical information of the meteorological stations. The monthly mean daily global radiation data were obtained from the National Meteorological Information Center (NMIC), China Meteorological Administration (CMA). The period of records range from 6 to 30 years covering the period between 1961 and 2000. Quality control tests were conducted by the suppliers. A year with more than 5 days of missing or faulty data in the same month was discarded (e.g., the year of 1992 for Nanchang and the year of 1984 for Wuhan). For each station, two data sets were created. About $70 \%$ of the total records were used for calibrating the parameters, and the remainder for evaluating the model (Table 1).

Table 1. Detailed information of the studied 14 stations in the Yangtze River basin

\begin{tabular}{c|c|c|c|c|c|c}
\hline $\begin{array}{c}\text { Station } \\
\text { ID }\end{array}$ & $\begin{array}{c}\text { Station } \\
\text { name }\end{array}$ & $\begin{array}{c}\text { Latitude } \\
(\mathbf{N})\end{array}$ & $\begin{array}{c}\text { Longitude } \\
(\mathbf{E})\end{array}$ & $\begin{array}{c}\text { Altitude } \\
(\mathbf{m})\end{array}$ & $\begin{array}{c}\text { Calibration } \\
\text { period }\end{array}$ & $\begin{array}{c}\text { Validation } \\
\text { period }\end{array}$ \\
\hline 1 & Chengdu & 30.67 & 104.02 & 506 & $1973-1992$ & $1993-2000$ \\
2 & Chongqing & 29.58 & 106.47 & 259 & $1973-1992$ & $1993-2000$ \\
3 & Changsha & 28.22 & 112.92 & 68 & $1987-1996$ & $1997-2000$ \\
4 & Hefei & 31.87 & 117.23 & 28 & $1978-1992$ & $1993-2000$ \\
5 & Hangzhou & 30.23 & 120.17 & 42 & $1973-1992$ & $1993-2000$ \\
6 & Lijiang & 26.83 & 100.47 & 2394 & $1977-1992$ & $1993-2000$ \\
7 & Nanchong & 30.78 & 106.10 & 309 & $1874-1985$ & $1986-1990$ \\
8 & Nanchang & 28.60 & 115.92 & 47 & $1973-1991$ & $1993-2000$ \\
9 & Nanjing & 32.00 & 118.80 & 9 & $1973-1992$ & $1993-2000$ \\
10 & Shanghai & 31.17 & 121.43 & 3 & $1961-1983$ & $1983-1990$ \\
11 & Wuhan & 30.62 & 114.13 & 23 & $1973-1983$ & $1993-2000$ \\
12 & Yichang & 30.70 & 111.30 & 133 & $1973-1992$ & $1993-2000$ \\
13 & Zunyi & 27.7 & 106.88 & 844 & $1973-1984$ & $1985-1990$ \\
14 & Guiyang & 26.58 & 106.72 & 1074 & $1973-1992$ & $1993-2000$ \\
\hline
\end{tabular}

\section{Models and calibration}

The extra-terrestrial solar radiation $(\mathrm{Ra})$ and potential sunshine duration $(\mathrm{Ho})$ are calculated using the equations (Eqs. 2-6) detailed by Allen et al., (1998).

$$
\begin{gathered}
R a=37.6 d(\omega \sin \phi \sin \delta+\cos \phi \cos \delta \sin \omega) \\
d=1+0.033 \cos \left(\frac{2 \pi}{365} n\right) \\
\delta=0.4093 \sin \left(\frac{2 \pi}{365} n-1.39\right) \\
\omega=\arccos (-\tan \phi \tan \delta)
\end{gathered}
$$




$$
H o=24 \omega / \pi
$$

where $d$ is the relative distance between the sun and the earth, $\omega$ is sunset hour angle ( $\mathrm{rad}), \varphi$ is latitude ( $\mathrm{rad}), \delta$ is solar declination angle ( $\mathrm{rad}), n$ is the number of the day of year starting from the first of January. The A-P model parameters $a$ and $b$ are calibrated by least square linear regression between $R s / R a$ and $H / H o$ for the calibration period for each station (Table 1).

\section{Performance criteria}

To assess the performance of models, root mean square error (RMSE), relative root mean square Error (RRMSE), The relative percentage error (e\%), coefficient of variation $(\mathrm{CV})$ and coefficient of determination $\left(\mathrm{R}^{2}\right)$ are determined. The metric $\mathrm{CV}$ calculated as ratio of standard deviation to arithmetic mean is adopted to measure the variation of the parameter, and $\mathrm{R}^{2}$ is adopted to measure the correlation between the observed and predicted values. The former three indicators are calculated by Equations 7-9.

$$
\begin{aligned}
\text { RMSE } & =\sqrt{\frac{\sum_{i=1}^{n}\left(y_{i}-\hat{y}_{i}\right)^{2}}{n}} \\
\text { RRMSE } & =\frac{1}{y} \sqrt{\frac{\sum_{i=1}^{n}\left(y_{i}-\hat{y}_{i}\right)^{2}}{n}} \\
e & =\frac{100\left(\hat{y}_{i}-y_{i}\right)}{y_{i}}
\end{aligned}
$$

where $n, y, \hat{y}$ and $\bar{y}$ represent the number of testing data, the observation value, the predicted value and the average value of the observation, respectively. Lower values of RMSE, RRMSE, and absolute e\% indicate a better estimation accuracy of the model.

\section{Results and discussion}

\section{Variation of A-P model parameters}

The calibrated A-P model parameters $a$ and $b$ are summarized in Table 2. Parameter $a$ vary from 0.103 in Hefei to 0.225 in Lijiang (averaged 0.137, SD $=0.031$ ), $b$ vary from 0.550 in Chengdu to 0.621 in Changsha (averaged 0.579, $\mathrm{SD}=0.017$ ), and $\mathrm{R}^{2}$ vary from 0.718 to 0.915 (averaged $0.831, \mathrm{SD}=0.062$ ). Obviously, parameter $b$ is more stable with the lowest SD (0.017) and CV (2.858\%) in the present study area, while parameter a show a higher variation with the CV of $22.534 \%$.

The values of $\mathrm{R}^{2}$ indicate that the linear function gave goodness of fit on the calibration data; however, some researchers studied and proposed several types of regression models on the corresponding calibration data at specific sites, such as, quadratic (Ogelman et al., 1984; Akinoglu and Ecevit, 1990), cubic (Bahel et al., 1987; Ertekin and Yaldiz, 2000), and logarithmic models (Newland, 1988; Ampratwum and 
Dorvlo, 1999). Table 2 presents the coefficient of determination of quadratic, cubic, logarithmic and power functions. All the regression equations give goodness of fit on the calibration data, with the values of $\mathrm{R}^{2}>0.7$. The linear A-P, quadratic and cubic models return quite similar values of $\mathrm{R}^{2}$ within the same station, and the cubic model is the best with the highest values of $\mathrm{R}^{2}$. However, it is noted that it is only slightly better. The logarithmic and power function even gives the worse fit than the simple linear A-P model. Therefore, there is no reason to choose a complex function to gain probably negligible accuracy at the cost of losing the simplicity and convenience of the simple AP model (Liu et al., 2009).

Table 2. The calibrated parameters of linear model and coefficient of determination of quadratic, cubic, logarithmic and power functions at 14 stations in the study area

\begin{tabular}{c|c|c|c|c|c|c|c|c}
\hline \multirow{2}{*}{ Stations } & \multicolumn{4}{|c|}{ Linear model } & Quadratic & Cubic & Logarithmic & Power function \\
\cline { 2 - 9 } & $\mathbf{a}$ & $\mathbf{b}$ & $\mathbf{a}+\mathbf{b}$ & $\mathbf{R}^{\mathbf{2}}$ & $\mathbf{R}^{\mathbf{2}}$ & $\mathbf{R}^{\mathbf{2}}$ & $\mathbf{R}^{\mathbf{2}}$ & $\mathbf{R}^{\mathbf{2}}$ \\
\hline Chengdu & 0.164 & 0.55 & 0.714 & 0.747 & 0.757 & 0.758 & 0.732 & 0.744 \\
Chongqing & 0.119 & 0.585 & 0.703 & 0.867 & 0.878 & 0.878 & 0.781 & 0.792 \\
Changsha & 0.125 & 0.621 & 0.746 & 0.867 & 0.875 & 0.875 & 0.827 & 0.815 \\
Hefei & 0.103 & 0.59 & 0.693 & 0.773 & 0.777 & 0.777 & 0.765 & 0.720 \\
Hangzhou & 0.127 & 0.568 & 0.694 & 0.718 & 0.786 & 0.787 & 0.750 & 0.768 \\
Lijiang & 0.225 & 0.576 & 0.801 & 0.873 & 0.874 & 0.875 & 0.831 & 0.946 \\
Nanchong & 0.155 & 0.583 & 0.738 & 0.872 & 0.872 & 0.873 & 0.765 & 0.845 \\
Nanchang & 0.12 & 0.579 & 0.7 & 0.915 & 0.921 & 0.920 & 0.886 & 0.920 \\
Nanjing & 0.13 & 0.578 & 0.709 & 0.781 & 0.783 & 0.784 & 0.744 & 0.788 \\
Shanghai & 0.158 & 0.565 & 0.723 & 0.872 & 0.873 & 0.872 & 0.849 & 0.860 \\
Wuhan & 0.11 & 0.564 & 0.674 & 0.771 & 0.772 & 0.773 & 0.746 & 0.737 \\
Yichang & 0.12 & 0.594 & 0.713 & 0.811 & 0.813 & 0.816 & 0.751 & 0.779 \\
Zunyi & 0.131 & 0.58 & 0.711 & 0.895 & 0.918 & 0.918 & 0.781 & 0.807 \\
Guiyang & 0.133 & 0.582 & 0.714 & 0.87 & 0.873 & 0.874 & 0.797 & 0.832 \\
Minimum & 0.103 & 0.55 & 0.674 & 0.718 & 0.757 & 0.758 & 0.732 & 0.720 \\
Maximum & 0.225 & 0.621 & 0.801 & 0.915 & 0.921 & 0.920 & 0.886 & 0.946 \\
Mean & 0.137 & 0.579 & 0.717 & 0.831 & 0.841 & 0.841 & 0.786 & 0.811 \\
SD & 0.031 & 0.017 & 0.03 & 0.062 & 0.057 & 0.056 & 0.046 & 0.066 \\
CV & $22.53 \%$ & $2.86 \%$ & $4.25 \%$ & $7.46 \%$ & $6.76 \%$ & $6.71 \%$ & $5.85 \%$ & $8.11 \%$ \\
\hline
\end{tabular}

\section{Relationship between the parameters and geographical information}

Generally, the A-P model parameters vary from station to station as shown in Table 2. To find out the relationship between the parameters and station geographical information, the correlation analysis is carried out and a summary is presented in Table 3.

Parameters $a, b$, the sum $a+b$ show very weak correlation with latitude (p >0.05). While parameter $a$, and the sum $a+b$ are correlated most significantly with altitude $(\mathrm{r}=0.786, \mathrm{p}=0.0009$, and $\mathrm{r}=0.746, \mathrm{p}=0.0022$, respectively), and less significantly with longitude $(\mathrm{r}=-0.532, \mathrm{p}=0.0403$, and $\mathrm{r}=-0.535, \mathrm{p}=0.0486$, respectively), one probable explanation is in that the significantly correlation between the altitude and longitude of the study area $(r=0.933, p=0.00254<0.001)$. 
Table 3. Correlation coefficients between A-P model parameters and geographical information

\begin{tabular}{c|c|c|c}
\hline Geographical information & $\mathbf{a}$ & $\mathbf{b}$ & $\mathbf{a}+\mathbf{b}$ \\
\hline Latitude & -0.346 & 0.246 & 0.485 \\
Longitude & $-0.532^{*}$ & -0.009 & $-0.535^{*}$ \\
Altitude & $0.786^{* *}$ & 0.096 & $0.746^{* *}$ \\
\hline
\end{tabular}

*Significant at 0.05 significance level

** Significant at 0.01 significance level

Parameter $a$ represents the overall atmospheric transmission for total cloud conditions, and the sum $a+b$ denotes the overall atmospheric transmission under clear sky conditions (Podesta et al., 2004). The correlations indicate a general increasing trend for $a$ and the sum $a+b$ as the altitude increasing from east to west in the study area, indicating that the highland western area tends to have more clear days than the lowland eastern area, this maybe the effect of reduced air mass and shorter path length at the high altitude (Liu et al., 2009).

\section{Estimating A-P model parameters using the geographical information}

The significant correlations are important in increasing the availability of A-P model parameters without the need for calibration. Parameters $a$, and sum $a+b$ correlate most significantly with altitude (Table 3), based on these correlations, we propose equations relating A-P model parameters to the most dominant factor (altitude). The regression functions between parameters $a$, sum $a+b$ and altitude are given below (Eqs. 10-11), respectively.

$$
\begin{gathered}
a=4 \times 10^{-5} \text { Altitude }+0.1221 \\
\text { sum }=3 \times 10^{-5} \text { Altitude }+0.7025
\end{gathered}
$$

where altitude is the elevation of the station in $\mathrm{m}$, sum is the sum of parameter $a$ and $b$. Consequently, the determination equation $(E q .12)$ of parameter $b$ is calculated by subtracting Equation10 from Equation11:

$$
b=-10^{-5} \text { Altitude }+0.5804
$$

The A-P model parameters estimated by the corresponding model and the performances are listed in Table 4. Overall, all the models give good performances with RMSE $\leq 0.02$ and RRMSE $<14 \%$; better performances are found in estimation of sum $a+b$ and $b$, with the absolute e $\%<6 \%$, and $<7 \%$, RMSE of 0.020 , and 0.017 , RRMSE of $2.76 \%$, and $2.92 \%$, respectively; while the RMSE of 0.019 and RRMSE of $13.54 \%$ in estimation of parameter $a$. Obviously, the mean of estimated parameters $a, b$, and sum $a+b$ are nearly identical to those of calibrated parameters (Tables 4 and 2), with the slightly differences of $0.001,0.003$, and 0.002 , respectively. The estimated parameter $a$ are much lower than the suggested values by Ångström and Prescott (Chen and Li, 2013), Page (1961) and FAO (Allen et al., 1998), while parameter $b$ are larger. 
Table 4. The estimated A-P model parameters at 14 stations in the study area

\begin{tabular}{c|c|c|c|c|c|c}
\hline Stations & $\mathbf{a}$ & $\mathbf{e \%}$ & $\mathbf{b}$ & $\mathbf{e} \%$ & $\mathbf{a}+\mathbf{b}$ & $\mathbf{e} \%$ \\
\hline Chengdu & 0.142 & -13.05 & 0.575 & 4.65 & 0.718 & 0.59 \\
Chongqing & 0.132 & 11.78 & 0.578 & -1.18 & 0.710 & 1.01 \\
Changsha & 0.125 & -0.38 & 0.580 & -6.63 & 0.705 & -5.58 \\
Hefei & 0.123 & 19.75 & 0.580 & -1.61 & 0.703 & 1.57 \\
Hangzhou & 0.124 & -2.15 & 0.580 & 2.20 & 0.704 & 1.41 \\
Lijiang & 0.218 & -3.26 & 0.556 & -3.41 & 0.774 & -3.37 \\
Nanchong & 0.134 & -13.25 & 0.577 & -0.94 & 0.712 & -3.53 \\
Nanchang & 0.124 & 2.97 & 0.580 & 0.13 & 0.704 & 0.62 \\
Nanjing & 0.122 & -6.09 & 0.580 & 0.35 & 0.703 & -0.84 \\
Shanghai & 0.122 & -22.79 & 0.580 & 2.77 & 0.703 & -2.82 \\
Wuhan & 0.123 & 11.63 & 0.580 & 2.92 & 0.703 & 4.35 \\
Yichang & 0.127 & 6.36 & 0.579 & -2.45 & 0.706 & -0.97 \\
Zunyi & 0.156 & 18.98 & 0.572 & -1.42 & 0.728 & 2.34 \\
Guiyang & 0.165 & 24.57 & 0.570 & -2.09 & 0.735 & 2.86 \\
Mean & 0.138 & 2.505 & 0.576 & -0.479 & 0.715 & -0.170 \\
RMSE & 0.019 & - & 0.017 & - & 0.020 & - \\
RRMSE & $13.54 \%$ & - & $2.92 \%$ & - & $2.76 \%$ & - \\
\hline
\end{tabular}

\section{Estimating solar radiation using the estimated parameters}

The A-P model with the parameters a determined by Equation 10, and b by Equation 12 is consequently used to estimate solar radiation and the performance is presented in Figure 2. Overall, it gives good estimation performance with RMSE $<1.7 \mathrm{MJ} \mathrm{m}^{-2}$ (averaged 1.182 $\mathrm{MJ} \mathrm{m}^{-2}$ ), RRMSE < 20\% (averaged 11.48\%) and $\mathrm{R}^{2}>0.89$ (averaged 0.940 ). There is a substantially good agreement between estimated and observed values as shown in Figure 2, where the points tend to line up around the 1:1 line, indicating that the observed solar radiation are close to the estimated.

Yangtze River basin is one of the major grain production areas of China and hence the eco-environmental models and crop growth simulation are widely studied. Therefore, solar radiation estimation using these measured meteorological variables is of vital importance and significance. Some works have reported the validation of the existing solar radiation in Yangtze River basin. Chen et al. (2004) introduced a new model using ambient temperature and A-P model at 10 sites in Yangtze River basin. While the new model was reported to give similar fit with A-P model at Nanchang station (Wu et al., 2007). In another work, Chen et al. (2006) modified the A-P model at 10 sites in Yangtze River basin. Comparing our general model with their site-specific models, the model give similar performance at most sties in Yangtze River basin, suggesting that the general model have great potential practical applications in agriculture, environment and ecology. 

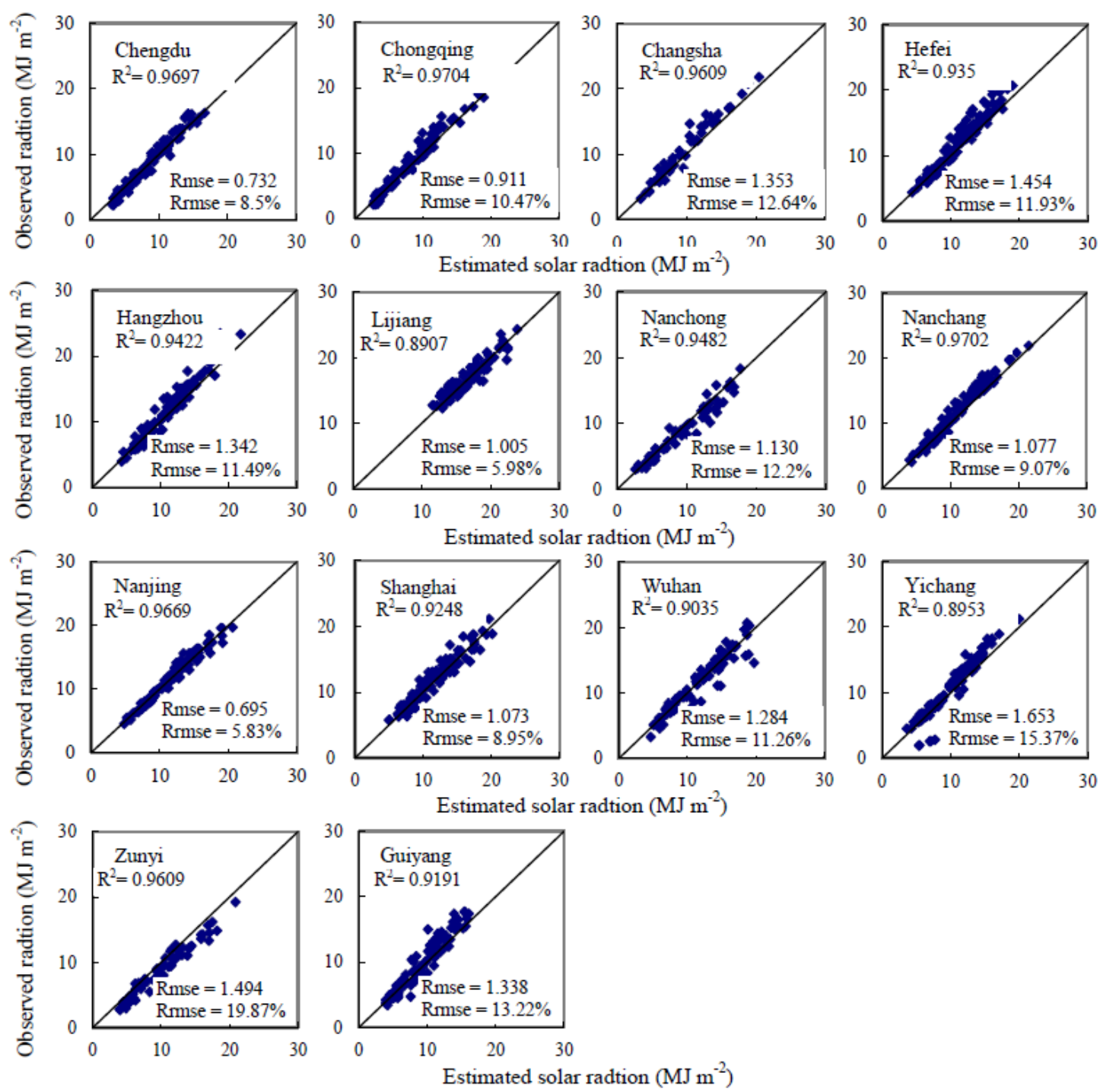

Figure 2. Scatter plots of the observed vs. estimated radiation at 14 stations in Yangtze River basin

\section{Conclusion}

Solar radiation is an essential and important variable to many simulation models. Ångström-Prescott model is widely used to estimate solar radiation when it is not readily available. The commonly used modifications to the Ångström-Prescott model, including the linear, second and cubic regression equations, give very similar goodness of fit and accuracy. Therefore, the simple Ångström-Prescott model is recommended in Yangtze River basin in China, due to its greater simplicity and convenience. Parameter $a$, sum $a+b$ correlate significantly with altitude. The deterministic equations for parameters $a$ and $b$ are given, and good estimation accuracy are obtained. Consequently, the Angström-Prescott model with the parameters by corresponding deterministic equations is evaluated. Overall, it gives good estimation performance according to the performance indicators of root mean square error, relative root mean square error, coefficient of determination. Therefore, it is recommended to use these equations to determine the corresponding parameters in Yangtze River basin in China, and it is 
believed particularly useful for the site where no observation of solar radiation data is available for calibration. Besides sunshine duration, air temperature, relative humidity, precipitation and atmospheric pressure are also routinely measured. Many works have shown that models using these meteorological variables in combination with sunshine duration significantly outperformed models using sunshine duration alone (Trabea and Shaltout, 2000; Liu et al., 2012). Thus, future work will investigate the potential of models using more combination of meteorological variables to increase the reliability of the general model.

Acknowledgements. The work was supported by Youth Innovation Promotion Association (Chen ji long), National Natural Science Foundation of China (41401051), STS project (KFJ-SW-STS-180) Chongqing Science and Technology project (KJ-2017026, cstc2015jcyjA00007), Fuling Science and Technology project (2016ABB1040), Opening Fund of Key Laboratory of Poyang Lake Wetland and Watershed Research, Ministry of Education (WE2016002, ZK2015001). We thank the National Meteorological Information Center, China Meteorological Administration for providing the long-term data records.

\section{REFERENCES}

[1] Abraha, M. G., Savage, M. J. (2008): Comparison of estimates of daily solar radiation from air temperature range for application in crop simulations. - Agricultural and Forest Meteorology 148: 401-416.

[2] Akinoglu, B. G. Ecevit, A. (1990): Construction of a quadratic model using modified Ångström coefficients to estimate global solar radiation. - Solar Energy 45(2): 85-92.

[3] Allen, R. G., Pereira, L. S., Raes, D., Smith, M. (1998): Crop evapotranspiration. Guidelines for computing crop water requirements. - FAO Irrigation and Drainage paper 56, Rome.

[4] Ampratwum, D. B., Dorvlo, A. S. S. (1999): Estimation of solar radiation from the number of sunshine hours. - Applied Energy 63(3): 161-167.

[5] Bahel, V., Bakhsh, H., Srinivasan, R. (1987): A correlation for estimation of global solar radiation. - Energy 12(2): 131-135.

[6] Bandyopadhyay, A., Bhadra, A., Raghuwanshi, N. S, Singh, R. (2008): Estimation of monthly solar radiation from measured air temperature extremes. - Agricultural and Forest Meteorology 148(11): 1707-1718.

[7] Bristow, K. L. Campbell, G. S. (1984): On the relationship between incoming solar radiation and daily maximum and minimum temperature. - Agricultural and Forest Meteorology 31(2): 159-166.

[8] Chen, D. L, Yu, Q., Wu, D. R, Haginoya, S. (2012): Observation and calculation of the solar radiation on the Tibetan Plateau. - Energy Conversion and Management 57: 23-32.

[9] Chen, J. L., Li, G. S. (2013): Estimation of monthly average daily solar radiation from measured meteorological data in Yangtze River Basin in China. - International Journal of Climatology 33: 487-498.

[10] Chen, J.L., Li, G.S., Wu, S.J. (2013): Assessing the potential of support vector machine for estimating daily solar radiation using sunshine duration. - Energy Convers Manage 75: 311-318.

[11] Chen, J. L., Li, G. S. (2014): Evaluation of support vector machine for estimation of solar radiation from measured meteorological variables. - Theoretical and Applied Climatology 115: 627-638.

[12] Chen, J. L., Liu, H. B., Wu, W., Xie, D. T. (2011): Estimation of monthly solar radiation from measured temperatures using support vector machines - A case study. - Renewable Energy 36(1): 413-420. 
[13] Chen, J. L., Xiao, B. B., Chen, C. D., Wen, Z. F., Jiang, Y., Lv, M. Q., Li, G. S. (2014): Estimation of monthly-mean global solar radiation using MODIS atmospheric product over China. - Journal of Atmospheric and Solar-terrestrial Physics 110: 63-80.

[14] Chen, J. L., Xiao, B. B., Chen, C. D., Wen, Z. F., Jiang, Y., Lv, M. Q., Wu, S. J., Li, G. S. (2015): Estimation of solar radiation using two-step method in Yangtze River basin in China. - MAUSAM 66(2): 225-236.

[15] Chen, R. S., Ersi, K., Yang, J. P., Lu, S. H., Zhao, W. Z. (2004): Validation of five global radiation models with measured daily data in China. - Energy Conversion and Management 45: 1759-1769.

[16] Chen, R. S., Ersi, K., Ji, X. B., Yang, J. P., Zhao, W. Z. (2006): Trends of the global radiation and sunshine hours in 1961-1998 and their relationships in China. - Energy Conversion and Management 47: 2859-2866.

[17] Ertekin, C., Yaldiz, O. (2000): Comparison of some existing models for estimating global solar radiation for Antalya (Turkey). - Energy Conversion and Management 41(4): 3031.

[18] Frulla, L. A., Gagliardini, D. A., Grossi, G. H., Lopardo, R., Tarpley, J. D. (1988): Incident solar radiation on Argentina from the geostationary satellite GOES: comparison with ground measurements. - Solar Energy 41(1): 61-69.

[19] Hansen, J. W. (1999): Stochastic daily solar irradiance for biological modeling applications. - Agricultural and Forest Meteorology 94(1): 53-63.

[20] Hargreaves, G. H., Samani, Z. A. (1982): Estimating potential evapotranspiration. - J. Irrg. Drain. Engrg. ASCE 108: 225-230.

[21] Iziomon, M. G., Mayer, H. (2002): Assessment of some global solar radiation parameterizations. - Journal of Atmospheric and Solar-Terrestrial Physics 64(15): 16311643.

[22] Liu, J. D., Pan, T., Chen, D. L., Zhou, X. J., Yu, Q., Flerchinger, G. N., Liu, D. L., Zou, X. T., Linderholm, H. W., Du, J., Wu, D. R. (2017): An improved Ångström-type model for estimating solar radiation over the Tibetan Plateau. - Energies 10(7): 892-901.

[23] Liu, X. Y., Mei, X. R., Li, Y. Z., Zhang, Q., Wang, Q. S. (2009): Calibration of the Angström-Prescott coefficients $(\mathrm{a}, \mathrm{b})$ under different time scales and their impacts in estimating global solar radiation in the Yellow River basin. - Agricultural and Forest Meteorology 149(3): 697-710.

[24] Miller, D. G., Rivington, M., Matthews, K. B., Buchan, K., Bellocchi, G. (2008): Testing the spatial applicability of the Johnson-Woodward method for estimating solar radiation from sunshine duration data. - Agricultural and Forest Meteorology 148(3): 466-480.

[25] Newland, F. J. (1988): A study of solar radiation models for the coastal region of South China. - Solar Energy 43(4): 227-235.

[26] Ögelman, H., Ecevit, A., Tasdemiroglu, E. (1984): A new method for estimating solar radiation from bright sunshine data. - Solar Energy 33(6): 619-625.

[27] Page, J. K. (1961): The estimation of monthly mean values of daily total short wave radiation on vertical and inclined surface from sunshine records for latitudes $40 \mathrm{~N}-40 \mathrm{~S}$. Proceedings of UN Conference on New Sources of Energy 4: 378-90.

[28] Podestá, G. P., Núňez, L., Villanueva, C. A., Skansi, M. A. (2004): Estimating daily solar radiation in the Argentine Pampas. - Agricultural and Forest Meteorology 123(1): 41-53.

[29] Richardson, C. W. (1981): Stochastic simulation of daily precipitation, temperature, and solar radiation. - Water Resources Research 17(1): 182-190.

[30] Thorton, P. E., Running, S. W. (1999): An improved algorithm for estimating daily solar radiation from measurements of temperature, humidity, and precipitation. - Agricultural and Forest Meteorology 93(4): 211-228.

[31] Trabea, A. A., Shaltout, M. A. M. (2000): Correlation of global solar radiation with meteorological parameters over Egypt. - Renewable Energy 21: 297-308. 
[32] Trnka, M., Zalud, Z., Eitzinger, J., Dubrovský, M. (2005): Global solar radiation in Central European lowlands estimated by various empirical formulae. - Agricultural and Forest Meteorology 131(1): 54-76.

[33] Wilks, D. S., Wilby, R. L. (1999): The weather generation game: a review of stochastic weather models. - Progress in Physical Geography 23: 329-357.

[34] Wu, G. F., Liu, Y. L., Wang, T. J. (2007): Global solar radiation with measured meteorological data. - A case study in Nanchang station, China. - Energy Conversion and Management 48: 2447-2452.

[35] Yorukoglu, M., Celik, A. N. (2006): A critical review on the estimation of daily global solar radiation from sunshine duration. - Energy Conversion and Management 47(15): 2441-2150. 